\title{
Nucleate Pool Boiling on Copper-Graphite Composite Surfaces and Its Enhancement Mechanism
}

\author{
David F. Chao* \\ NASA John H. Glenn Research Center at Lewis Field, Cleveland, Ohio 44135 \\ Nengli Zhang ${ }^{\dagger}$ \\ Ohio Aerospace Institute, Cleveland, Ohio 44142 \\ and \\ Wen-Jei Yang \\ University of Michigan, Ann Arbor, Michigan 48109-2125
}

\begin{abstract}
An experimental study is performed on nucleate pool boiling in a highly wetting liquid, Freon-113, and a moderately wetting liquid, water, on copper-graphite $(\mathrm{Cu}-\mathrm{Gr})$ composite surfaces under atmospheric conditions. Boiling heat-flux data on the $\mathrm{Cu}-\mathrm{Gr}$ surfaces are compared with those on a pure copper surface. Best-fit correlation equations are derived to relate the boiling heat flux to wall superheat and boiling heat-transfer coefficient with the heat flux for each liquid-solid combination. It is disclosed that the nucleate boiling heat transfer in both test liquids is augmented by the presence of graphite fibers and that the composite surface with $25 \%$ volume fraction of graphite fibers in the copper matrix exhibited the best enhancing performance in both test liquids. Water is characterized by a stronger enhancement and less degeneracy of the enhancement with an increase in the heat flux than Freon-113. The enhancement mechanism is proposed using a bubble departure model developed by the authors.
\end{abstract}

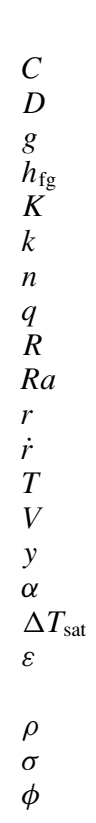

$=$ constant

$=$ bubble departure diameter, $\mathrm{m}$

$=$ gravitational acceleration, $\mathrm{m} / \mathrm{s}^{2}$

$=$ latent heat, $\mathrm{kJ} / \mathrm{kg}$

enhancement factor

$=$ thermal conductivity, $\mathrm{W} / \mathrm{mK}$

constant

$=$ heat flux, $\mathrm{W} / \mathrm{m}^{2}$

= bubble departure radius or curvature radius, $\mathrm{mm}$

average surface roughness, $\mu \mathrm{m}$

$=$ radius, $\mathrm{m}$

liquid velocity, $\mathrm{m} / \mathrm{s}$

temperature, $\mathrm{K}$

vapor velocity, $\mathrm{m} / \mathrm{s}$

vertical direction coordinate, $\mathrm{m}$

= boiling heat-transfer coefficient, $\mathrm{W} / \mathrm{m}^{2} \mathrm{~K}$

wall superheat, $\mathrm{K}$

$=$ ratio of bubble neck radius over equivalent radius of evaporation area at bubble foot

$=$ liquid density, $\mathrm{kg} / \mathrm{m}^{3}$

$=$ surface tension, $\mathrm{N} / \mathrm{m}$

$=$ volume fraction of graphite fibers in copper-graphite composite surface

Subscripts

\section{$\mathrm{cu}=$ copper}

Received 10 March 2003; revision received 8 September 2003; accepted for publication 9 September 2003. Copyright (C) 2003 by the American Institute of Aeronautics and Astronautics, Inc. The U.S. Government has a royalty-free license to exercise all rights under the copyright claimed herein for Governmental purposes. All other rights are reserved by the copyright owner. Copies of this paper may be made for personal or internal use, on condition that the copier pay the $\$ 10.00$ per-copy fee to the Copyright Clearance Center, Inc., 222 Rosewood Drive, Danvers, MA 01923; include the code 0887-8722/04 \$10.00 in correspondence with the CCC.

*Research Scientist, Microgravity Science Division, Mail Stop 77-5.

${ }^{\dagger}$ Senior Scientist, Department of Workforce Enhancement; currently at Microgravity Science Division, Mail Stop 77-5, NASA John H. Glenn Research Center at Lewis Field, Cleveland, Ohio 44135.

†Professor, Department of Mechanical Engineering.

$\begin{array}{ll}f & =\text { bubble foot } \\ \text { gr } & =\text { graphite } \\ i & =\text { interface } \\ k & =\text { enhancement factor } \\ l & =\text { liquid, or loss } \\ r & =\text { copper rod } \\ s & =\text { specimen } \\ t & =\text { bubble throat } \\ v & =\text { vapor } \\ w & =\text { wall }\end{array}$

\section{Introduction}

B OILING has been considered as an efficient heat-transfer mode in various aspects of space missions, such as thermal management, thermal power generation, cooling devices, and other heat exchangers. ${ }^{1-4}$ Studies of nucleate pool boiling on surfaces of pure substances have been extensively conducted to gain some insight into the complex phenomenon of flow boiling, which is of practical significance as a process. An improved understanding of boiling phenomena on plain surfaces led to the means for modifying the process through changing properties of the working fluid or/and the boiling surface in order to increase the boiling heat-transfer coefficient. Thome ${ }^{5}$ classified these enhancement techniques into passive and active categories with the former being of the most practical importance. Passive techniques include the use of treated, rough, and extended surfaces, and surface tension devices. Recently, a new passive technique employing metal-graphite composite surfaces was developed and studied..$^{6-14}$ It was shown that the nucleate pool boiling heat transfer in Freon-113 (a highly wetting liquid) on a copper-graphite $(\mathrm{Cu}-\mathrm{Gr})$ composite surface is augmented from four to six times over that of a pure copper surface. ${ }^{6,9}$ Figure 1 depicts a typical photomicrograph of a polished $\mathrm{Cu}-\mathrm{Gr}$ composite surface with a $50 \%$ graphite-fiber volume fraction. It is seen that $8-10-\mu \mathrm{m}$ diam graphite fibers of high thermal conductivity $(1200 \mathrm{~W} / \mathrm{m} \mathrm{K})$ are imbedded in a copper matrix. Those fibers protrude from the surface like fins whose tips appear as a rugged surface. A further enlargement (to over 10,000 times by means of a scanning electron microscope) shows that the tip surfaces are filled with a large number of microsized low-lying trenches and intermingled narrow grooves, which serve as nucleation sites during the boiling process. 


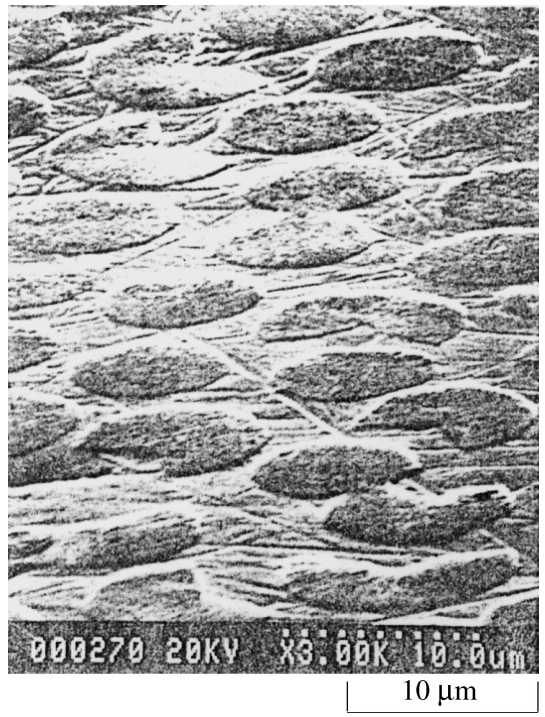

Fig. 1 Polished surface of $\mathrm{Cu}-\mathrm{Gr}$ composite with $50 \%$ graphite-fiber (8 $\sim 10 \mu \mathrm{m}$ diam) volume fraction.

The enhancement mechanisms of boiling on the composite surfaces are believed to be 1) relatively higher temperatures on the fiber tips because of the higher thermal conductivity of micro-graphite fibers contribute to the shortening of the bubble nucleation period, 2) a large number of embryo cavities of appropriate size activating nucleation at a lower surface superheat, and 3) the poorly wetted property of graphite fibers to prevent vapor in the cavities from being flooded by an intruding liquid upon immersion. ${ }^{14}$

Liang and Yang ${ }^{14}$ tested pentane (another highly wetting liquid) nucleate pool boiling performance on both $\mathrm{Cu}-\mathrm{Gr}$ and aluminumgraphite composite surfaces with a fiber volume concentration of $50 \%$. They concluded that the presence of graphite fibers not only enhanced overall boiling performance in the developed region but also reduced hysteresis effects in the startup region, which is important for the practical application of immersion cooling in the electronics industry. All experiments for pool boiling heat transfer on metal-graphite composite surfaces were conducted using highly wetting liquids. However, boiling heat transfer on these composite surfaces in water (a moderately wetting fluid) has not yet been investigated.

In the present study, experiments are conducted on nucleate pool boiling in a highly wetting liquid, Freon-113, and in a moderately wetting liquid, water, on $\mathrm{Cu}-\mathrm{Gr}$ composite surfaces with different fiber volume fractions, including 5, 25, and 50\%. In addition, experiments on a pure copper surface in both Freon-113 and water are also conducted to determine the role of graphite fibers in nucleate pool boiling. It is disclosed that boiling heat transfer in both Freon-113 and water is enhanced on the $\mathrm{Cu}-\mathrm{Gr}$ composite surface and that such an enhancement for water is higher than for Freon-113. The enhancement mechanism is analyzed with a bubble departure model proposed by the authors.

\section{Experimental Setup}

An experimental setup was fabricated to conduct pool boiling of both Freon-113 (a highly wetting liquid) and water (a moderately wetting fluid) on $\mathrm{Cu}-\mathrm{Gr}$ composite surfaces under atmospheric pressure. The experimental setup is schematically shown in Fig. 2. It consisted of the main heater assembly, test boiling surface, boiling vessel assembly, auxiliary heater, condenser assembly, data-acquisition system, and charge-coupled-device (CCD) cameravideo recorder system consisting of Sony CCD color video camera XC-999 (with four shutter speeds: 1/60, 1/100, 1/1,000 s, and automatically adjustable shutter speed-CCD IRIS mode) and Panasonic video recorder AG-7300. Heat was supplied from the solid copper block (designated \#3) of $45 \mathrm{~mm}$ in diameter and $95 \mathrm{~mm}$ in length through three $850-\mathrm{W}$ cartridge heaters (\#1) embedded in

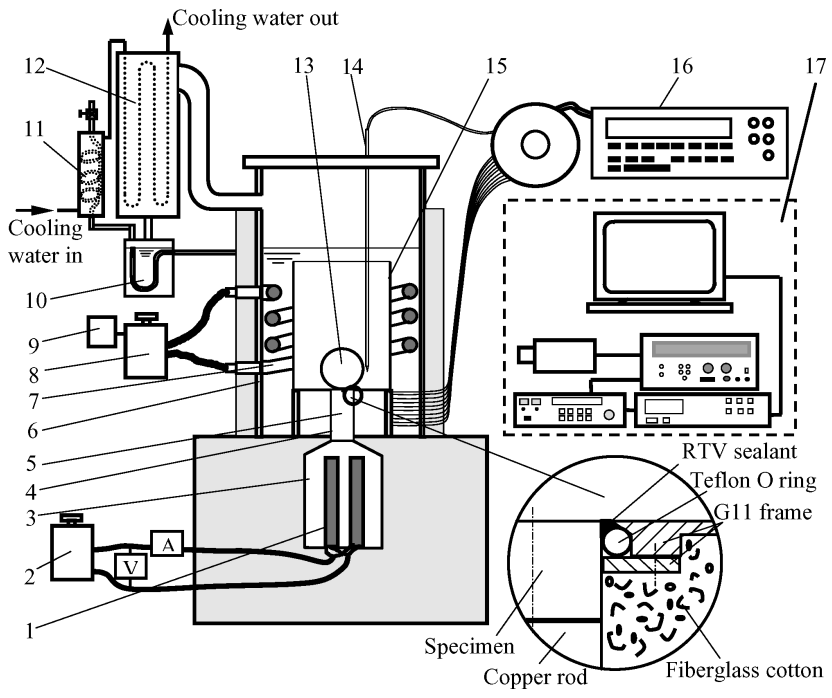

Fig. 2 Schematic of the experimental setup: 1) cartridge main heater assembly $(3 \times 850 \mathrm{~W}), 2)$ main heater variac $(0-120 \mathrm{~V}, 3.1 \mathrm{kVA}), 3)$ copper block, 4) copper rod, 5) thermocouples, 6) boiling vessel assembly, 7) auxiliary heater $(240 \mathrm{~V}, 1 \mathrm{~kW}), 8)$ auxiliary heater variac $(0-240 \mathrm{~V}$, $1.5 \mathrm{kVA})$, 9) step-up transfer $(120 \mathrm{~V} / 240 \mathrm{~V}), 10)$ condensate preheater, 11) auxiliary condenser, 12) main condenser, 13) optical window, 14) thermocouple probe, 15) glass shield, 16) digital temperature multimeter, and 17) CCD camera-video recorder system.

the block. A copper rod (\#4) of $25.4 \mathrm{~mm}$ in diameter and $50.8 \mathrm{~mm}$ in length was placed in a shallow blind hole of the copper block. It was used to conduct heat from the copper block to the heating surface, which was either the $\mathrm{Cu}-\mathrm{Gr}$ composite or the pure copper specimen. The prefabricated composite or the pure copper specimen of $25.4 \mathrm{~mm}$ in diameter and $10 \mathrm{~mm}$ in thickness sat on top of the copper rod. A thin layer of tin solder (not shown) was sandwiched between the rod and the copper block and also between the rod and the test specimen to form a heater-specimen assembly. The assembly was heated up to completely melt the solder, thus pressing them together. The top surface of each specimen, which served as the boiling surface, was polished to a average surface roughness value of $R a=1.6 \mu \mathrm{m}$ (grade N7) and was carefully covered with a plastic cap before the heater-specimen assembly was installed in the boiling vessel (\#6).

As depicted in the inset, the boiling surface was surrounded by a fiberglass-epoxy (G 11) extension frame with a Teflon ${ }^{\circledR}$ O-ring between them and sealed by high-temperature silicone sealant HI-TEMP RTV (Permatex \#26B) to prevent leakage. The low thermal conductivity of the Teflon O-ring and the G 11 frame ensured sufficient insulation of the boiling surface. Meanwhile the heaterspecimen assembly was insulated with fiberglass cotton to prevent lateral heat loss. Six calibrated thermocouples (\#5), made by copper and constantan wires of $0.089 \mathrm{~mm}$ in diameter, were installed at predetermined locations along the centerline of the heater-specimen assembly, three in the specimen and three in the copper rod, to monitor the temperature of the boiling surface and the temperature gradient along the heat-transfer path. Another six thermocouples (not shown) were mounted on the lateral surfaces of the specimen and the copper rod, at the same levels as the corresponding thermocouples at the centerline in order to evaluate the heat loss in the lateral direction.

The measured temperature profiles along the centerline and along the lateral surface of the heater-specimen assembly were extrapolated to the specimen surface, respectively, to determine the boiling surface temperatures at the center and the rim of the specimen and also evaluated the temperature gradients in the specimen to determine the heat fluxes to the boiling surface, taking the heat losses into account. The boiling vessel (\#6) of $140 \mathrm{~mm}$ in diameter and $305 \mathrm{~mm}$ long was made of Teflon tubing having two optical windows (\#13) for visualization, which could be removed for cleaning and polishing the boiling surface before each test run. An auxiliary heater 
(\#7), mounted in the boiling vessel against its inner wall, maintained the working fluid at saturation temperature. A glass shield (\#15) of $90 \mathrm{~mm}$ in diameter and $280 \mathrm{~mm}$ in length was attached to the G11 extension frame prevent the effects of convective currents induced by the auxiliary heater. The test liquid level was maintained at about $100 \mathrm{~mm}$ above the boiling surface. A calibrated thermocouple probe (\#14) was suspended at about $30 \mathrm{~mm}$ above the boiling surface to measure the saturation temperature. The vapor generated in the boiling vessel was condensed using cooling water circulated through the main condenser (\#12). The condensate was then heated in the preheater (\#10) to the saturation temperature before being returned to the boiling vessel. An auxiliary condenser (\#11) was used to prevent the escape of vapor in the preheater, which was open to the atmosphere in order to maintain the pressure within the experimental setup at atmospheric pressure. A CCD camera-video recorder system (\#17) was employed for visualization and recording of boiling phenomena on the boiling surface.

All thermocouples were calibrated by an Omega CL8300 highprecision calibrator using a platinum resistance thermometer. A digital temperature multimeter (\#16) (Omega OM-7563) was used to read the measured temperatures. The uncertainty of temperature measurements was estimated to be within $\pm 0.05 \mathrm{~K}$.

\section{Experimental Procedure}

Two sets of experiments were performed: 1) Freon-113 on a pure copper surface and on $\mathrm{Cu}-\mathrm{Gr}$ composite surfaces with three different volume fractions of graphite fiber, $\phi \approx 5,25$, and $50 \%$; and 2 ) distilled water on a pure copper surface and on $\mathrm{Cu}-\mathrm{Gr}$ composite surfaces with $\phi \approx 25$ and $50 \%$. The study was focused on the pool boiling heat transfer performance of Freon-113 and water on $\mathrm{Cu}-\mathrm{Gr}$ composite surfaces. The main purpose of the experiments on the pure copper surface was to check both the experimental setup and the measurement system through comparison with existing data.

Before each test, for Freon-113 the boiling surface was polished by $1-\mu \mathrm{m}$ alumina slurry produced by Electron Microscopy Sciences to remove any oxidation and deposition, then subsequently cleaned with acetone, whereas for water the boiling surface was polished using an aluminum-oxide abrasive compound and then cleaned using methanol. After pouring the test liquid into the boiling vessel, the auxiliary heater was turned on to vigorously boil the test liquid for about two hours for degassing. Subsequently, the power of the auxiliary heater was then reduced and adjusted to a specified level in order to maintain the test liquid temperature at its saturation state for at least one hour. Then, the main heater was turned on very slowly and gradually increased to a preset level. In the low heat-flux region, corresponding to less than $10^{4} \mathrm{~W} / \mathrm{m}^{2}$ for Freon- 113 and $10^{5} \mathrm{~W} / \mathrm{m}^{2}$ for water, the power input of the main heater was increased stepwise at an increment of about $10^{3} \mathrm{~W} / \mathrm{m}^{2}$ for Freon-113 and $10^{4} \mathrm{~W} / \mathrm{m}^{2}$ for water. In the moderate heat-flux region, corresponding to $10^{4}$ to $5 \times 10^{4} \mathrm{~W} / \mathrm{m}^{2}$ for Freon-113 and $10^{5}$ to $5 \times 10^{5} \mathrm{~W} / \mathrm{m}^{2}$ for water, the increment of the main heater power was about $0.5 \times 10^{4}$ for Freon-113 and $0.5 \times 10^{5} \mathrm{~W} / \mathrm{m}^{2}$ for water. To achieve steady state, various waiting periods ranging from $30 \mathrm{~min}$ to $1 \mathrm{~h}$ were imposed depending on time invariance of the thermocouple readings both in the specimen and in the copper rod. Extreme care was exercised in the higher heat-flux region to avoid the occurrence of premature film boiling. For such cases, in order to achieve a new steady state, the power input to the main heater was increased gradually, in steps of no more than $0.2 \times 10^{4} \mathrm{~W} / \mathrm{m}^{2}$ for Freon-113 and $0.2 \times 10^{5}$ $\mathrm{W} / \mathrm{m}^{2}$ for water, within a time interval of $30 \mathrm{~min}$. The power input devices were closely monitored and continuously adjusted to precisely maintain a preset power increment. After the power input reached a predetermined level through the multistep procedure and a new steady state achieved, the test liquid was allowed to boil at steady-state conditions for one hour before recording data.

\section{Data Reduction and Uncertainty}

The key data to retrieve in these experiments were the temperatures measured in the heater-specimen assembly and in the boiling vessel. Both the heat flux and the boiling surface temperature were determined from these data. The heat flux was calculated as
Table 1 Uncertainties for different cases

\begin{tabular}{lll}
\hline \hline & \multicolumn{2}{c}{ Relative uncertainty } \\
\cline { 2 - 3 } Case & High heat-flux region, $\%$ & Low heat-flux region, $\%$ \\
\hline Freon-113 & $38 \sim 58$ & \\
Pure copper & $37 \sim 55$ & $40 \sim 64$ \\
$\phi<5 \%$ & $28 \sim 39$ & $38 \sim 56$ \\
$\phi=25 \%$ & $27 \sim 36$ & $29 \sim 42$ \\
$\phi=50 \%$ & $32 \sim 37$ & \\
Water & $25 \sim 39$ & $28 \sim 33$ \\
$\phi=25 \%$ & $\sim 39$ & $25 \sim 37$ \\
$\phi=50 \%$ & & \\
\hline \hline
\end{tabular}

$q=k_{s}(\mathrm{~d} T / \mathrm{d} y)_{s}$ where $k_{s}$ is the conductivity of the test specimen and $(\mathrm{d} T / \mathrm{d} y)_{s}$ is the temperature gradient in the test specimen at the boiling surface. The value of $k_{s}$ was determined by the following relation:

$$
k_{\mathrm{cu}}\left(\frac{\mathrm{d} T}{\mathrm{~d} y}\right)_{i, r}-q_{l}=k_{s}\left(\frac{\mathrm{d} T}{\mathrm{~d} y}\right)_{i, s}
$$

where $k_{\mathrm{cu}}$ is the conductivity of copper; $(\mathrm{d} T / \mathrm{d} y)_{i, r}$ is the temperature gradient in the copper rod at the rod-specimen interface; $q_{l}$ is the radial heat loss in the rod; and $(\mathrm{d} T / \mathrm{d} y)_{i, s}$ is the temperature gradient in the test specimen at the rod-specimen interface. Both the temperature gradients in the copper rod and in the test specimen were determined by the temperature profile along the heat-transfer path. Hence, the accuracy of the thermocouple locations was very crucial, especially in the specimen with short distances between the thermocouples. The accuracy of thermocouple locations was controlled to within $0.1 \mathrm{~mm}$, such that the relative uncertainty of the conductivity of the $\mathrm{Cu}-\mathrm{Gr}$ composite was within approximately $9.1 \%$ and that of the heat flux was within about $12 \%$ for water and $16 \%$ for Freon-113. Several nucleate boiling tests were conducted for water on pure copper at different heat fluxes ranging from $4 \times 10^{4}$ to $7 \times 10^{5} \mathrm{~W} / \mathrm{m}^{2}$ for a debugging check of both the experimental setup and the measurement system at a first-order replication level. This procedure was considered suitable for time-wise experiments using the same set of instruments, in which some inevitable time variations of the measured parameter appeared as random errors in a series of measurements of the parameter over a period of time. ${ }^{15}$ Results agreed well with the regression equation of Gaertner within the scatter of Gaertner's data. ${ }^{16}$

Runs were repeated for Freon-113 and water boiling on the $\mathrm{Cu}-\mathrm{Gr}$ composite surfaces at different heat fluxes to check the first-order replication of the boiling heat-transfer data. The regression equations for each liquid-solid combination case were obtained using the least-mean-square method. The uncertainties for the cases tested in the present study are listed in Table 1 . The degree of data scatters shown in Figs. 3 and 4, which imply the uncertainties listed in Table 1, are not uncommon in nucleate boiling experiments. Because the measurements were made in a random manner over a period of a few months, the scatters of the data could be results of variations in the surface properties and/or caused by small changes in the calibration of the thermocouples.

\section{Results and Discussion}

\section{Experimental Results}

The pool nucleate boiling heat-transfer data for Freon-113 on a pure copper surface and on $\mathrm{Cu}-\mathrm{Gr}$ composite surfaces with $\phi=0.5$, 25, and 50\% are shown in Fig. 3. The data were obtained at heat fluxes up to $3 \times 10^{5} \mathrm{~W} / \mathrm{m}^{2}$. The data clearly show that the boiling heat-transfer performance of Freon-113 on $\mathrm{Cu}-\mathrm{Gr}$ composite surfaces is much higher than on a pure copper surface. The composite surface with $\phi=25 \%$ shows the highest rate of boiling heat transfer. This amounted to 6.7-fold increase in heat flux in the discrete bubble region and two-fold increase in the vapor mushroom region as compared to that on a pure copper surface. Meanwhile the composite surfaces with $\phi=5$ and $50 \%$ augmented the heat flux by factors of 1.2 and 1.6 in the high heat-flux region and 2.3 and 4.1 in the 


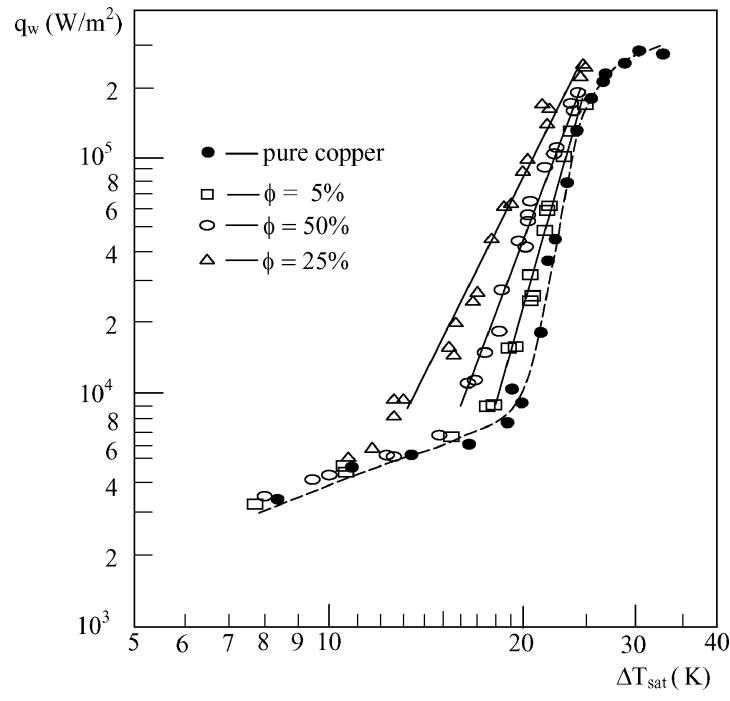

Fig. 3 Experimental data for Freon-113 pool boiling on pure copper surface and on $\mathrm{Cu}-\mathrm{Gr}$ composite surfaces $(\phi=5,25$, and $50 \%)$.

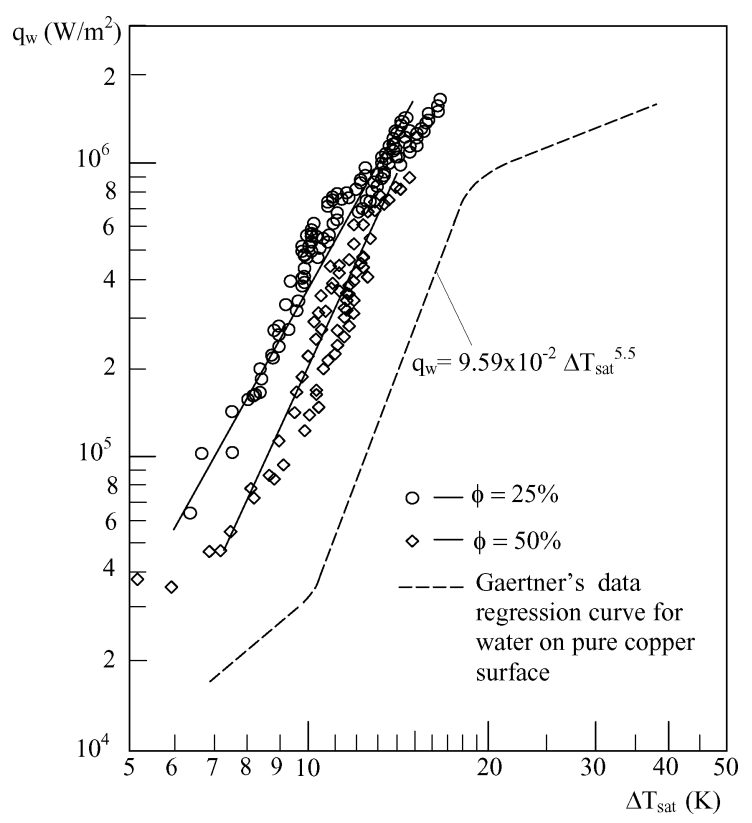

Fig. 4 Experimental data for water pool boiling on $\mathrm{Cu}-\mathrm{Gr}$ composite surfaces with $\phi=25$ and $50 \%$.

low heat-flux region for nucleate boiling. The results are in accord with Yang et al.'s conclusion. ${ }^{6,10}$ A linear regression analysis was performed on the experimental data in the nucleate boiling region, which yields the regression equation

$$
q_{w}=C \Delta T_{\mathrm{sat}}^{n}
$$

where $q_{w}$ is the boiling heat flux; $\Delta T_{\text {sat }}$ is wall superheat (the temperature difference between the boiling surface and the saturated working fluid); and $C$ and $n$ are empirical constants obtained by means of data fitting through the first-order regression of $q_{w}$ vs $\Delta T_{\text {sat }}$. The values of $C$ and $n$ thus determined for both pure copper and the $\mathrm{Cu}-\mathrm{Gr}$ composite surfaces are listed in Table 2.

The experimental boiling results for water on $\mathrm{Cu}-\mathrm{Gr}$ composite surfaces with $\phi=25$ and $50 \%$ are shown in Fig. 4. These results exhibit greater enhancements than those for Freon-113 in Fig. 3. The regressive curve of Gaertner ${ }^{16}$ for water on the pure copper surface is superimposed on Fig. 4 for reference. Consistent results are obtained in Fig. 4 showing that the composite surface with $\phi=25 \%$ yields the best boiling performance, with a 10-fold increase in heat flux for the discrete bubble region and 5.7-fold increase for the vapor mushroom
Table 2 Experimentally determined constants in Eq. (2) for boiling Freon-113

\begin{tabular}{lcr}
\hline \hline Case & \multicolumn{1}{c}{$C$} & \multicolumn{1}{c}{$n$} \\
\hline Pure copper & $3.43 \times 10^{-16}$ & 14.87 \\
$\phi=5 \%$ & $9.95 \times 10^{-9}$ & 9.50 \\
$\phi=25 \%$ & $6.82 \times 10^{-3}$ & 5.43 \\
$\phi=50 \%$ & $1.49 \times 10^{-5}$ & 7.28 \\
\hline \hline
\end{tabular}

Table 3 Experimentally determined constants in Eq. (2) for boiling water

\begin{tabular}{lcc}
\hline \hline Case & $C$ & $n$ \\
\hline Pure copper $^{\mathrm{a}}$ & $9.59 \times 10^{-2}$ & 5.50 \\
$\phi=25 \%$ & 73.01 & 3.70 \\
$\phi=50 \%$ & 5.68 & 4.53 \\
\hline \hline
\end{tabular}

${ }^{\mathrm{a}}$ From Gaertner ${ }^{16}$ converted the units in the English Engineering System to SI units.

Table 4 Constants in Eq. (3)

\begin{tabular}{lcc}
\hline \hline Case & $C_{k}$ & $n_{k}$ \\
\hline Freon-113 & & \\
$\phi=5 \%$ & $2.90 \times 10^{7}$ & -5.37 \\
$\phi=25 \%$ & $1.98 \times 10^{13}$ & -9.44 \\
$\phi=50 \%$ & $4.34 \times 10^{10}$ & -7.59 \\
Water & & \\
$\phi=25 \%$ & $7.61 \times 10^{2}$ & -1.80 \\
$\phi=50 \%$ & $0.59 \times 10^{2}$ & -0.97 \\
\hline \hline
\end{tabular}

region as compared to the pure copper surface case. In contrast, the surface with $\phi=50 \%$ produces corresponding augmentations of 5.8 and 4.3 times for the discrete bubble region and the vapor mushroom region, respectively. The values of $C$ and $n$ determined from the experimental data are listed in Table 3.

The following is seen in Figs. 3 and 4:

1) Both Freon-113 and water on the composite surface with $\phi=25 \%$ have the best boiling heat-transfer performance.

2) At the same wall superheat for boiling heat flux, the boiling initiation is greatly reduced on the composite surfaces as compared to the pure copper surface. For example, boiling was initiated on the composite surface with $\phi=25 \%$ at a superheat of $13 \mathrm{~K}$ for Freon- 113 and $6 \mathrm{~K}$ for water, reduced by 35 and $40 \%$, respectively from the corresponding cases for the pure copper surface.

3) Different characteristics are observed at the incipience of boiling between Freon-113 and water. Although the nucleate boiling of Freon-113 on the $\mathrm{Cu}-\mathrm{Gr}$ composite surfaces is initiated at lower superheats, it is initiated at almost the same heat flux as that on the pure copper surface. In contrast, the incipient boiling of water on the composite surfaces occurs at not only lower superheats but also higher heat fluxes. In the nucleate boiling region, the augmentation reaches a maximum in the low heat-flux region but reduces with an increase in the heat flux, as characterized by convergence of the boiling curves toward that for the pure copper surface in the high heat-flux region. Let us define the enhancement factor $K$ as

$$
K=q_{\mathrm{wgr}} / q_{\mathrm{wcu}}=C_{k} \Delta T_{\mathrm{sat}}^{n_{k}}
$$

Here, $q_{\text {wgr }}$ is the boiling heat flux on $\mathrm{Cu}-\mathrm{Gr}$ surfaces; $q_{\text {wcu }}$ is the boiling heat flux on a pure copper surface; $C_{k}$ is the intercept of $K$ for $K-\Delta T_{\text {sat }}$ logarithmic coordinates; and $n_{k}$ is the slope of the $K-\Delta T_{\text {sat }}$ plot. Substituting Eq. (2) into Eq. (3) yields $C_{k}=C_{\mathrm{gr}} / C_{\mathrm{cu}}$ and $n_{k}=n_{\mathrm{gr}}-n_{\mathrm{cu}}$, where $C_{\mathrm{gr}}$ and $C_{\mathrm{cu}}$ are the constants in Eq. (2) for $\mathrm{Cu}-\mathrm{Gr}$ composite surfaces and a pure copper surface, respectively. Similarly, $n_{\mathrm{gr}}$ and $n_{\mathrm{cu}}$ are the powers in Eq. (2) for $\mathrm{Cu}-\mathrm{Gr}$ composite surfaces and a pure copper surface, respectively. The values of $C_{k}$ and $n_{k}$ for Freon-113 and water boiling on pure copper and coppergraphite composite surfaces are listed in Table 4.

Compared to the boiling of Freon-113, water produces not only greater enhancement on the pure copper surface but also less 


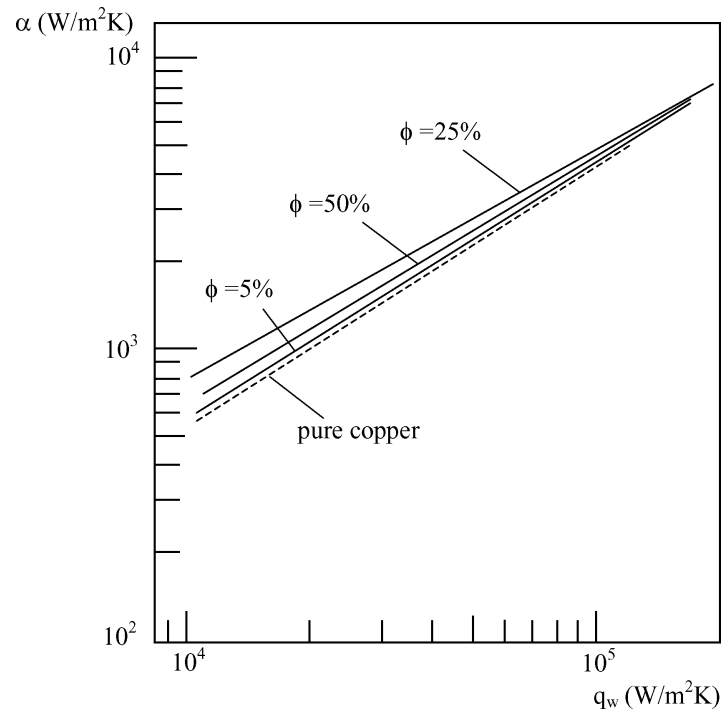

Fig. 5 Boiling convective heat-transfer coefficient of Freon-113 on different surfaces as a function of heat flux.

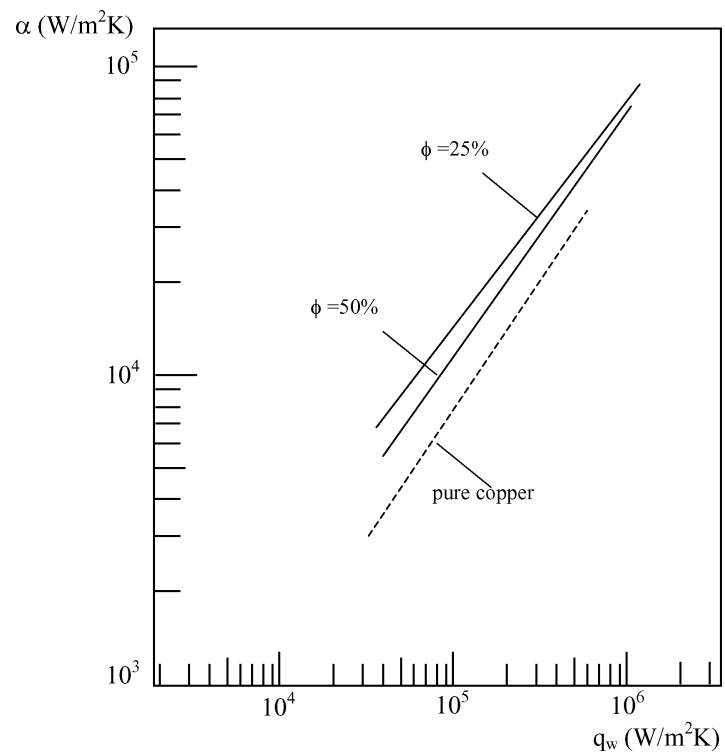

Fig. 6 Boiling convective heat-transfer coefficient of water on different surfaces as a function of heat flux.

degeneracy in enhancement with an increase in the heat flux. One can realize through an examination of the curves in Figs. 3 and 4 or by judging quantitatively from the variation of $n_{k}$ values in Table 4 that the smaller the $n_{k}$ is the faster the boiling curves for the composite surfaces converge toward that of a pure copper surface. The boiling heat-transfer coefficients, $\alpha$ that is defined as $q_{w} / \Delta T_{\text {sat }}$, are plotted against the heat flux in Figs. 5 and 6 for Freon-113 and water, respectively. It can be seen that the nucleate boiling heat-transfer coefficient achieves its highest value on the composite surface with $\phi=25 \%$, being up to 1.42 times for Freon-113 and 1.88 times for water, respectively, higher than the corresponding cases on the pure copper surface.

In our current experiments, both for boiling Freon-113 and boiling water, the critical heat flux (CHF) were close to but never reached because of the limitation of control instruments. Further research effort is putting on CHF. However, the existing experimental results at least show that $\mathrm{CHF}$ would occur at significantly lower superheat both for Freon-113 and water (see Figs. 3 and 4).

Obviously, an optimum graphite content exists around $\phi=25 \%$ (not exactly, of course, because the tested specimens were not of a continual spectrum of the graphite content) both for boiling Freon 113 and boiling water. It is likely a compromise between two contradictory factors: 1) more graphite fibers provide more potential nucleate sites, and 2) less spacing between adjacent graphite fibers increases the mutual interference among the embryo bubbles. More detailed discussion can be found in Ref. 10.

The primary mechanism of enhancing boiling heat transfer on the $\mathrm{Cu}-\mathrm{Gr}$ composite surfaces as compared to a pure copper surface can be attributed to bubble detachment characteristics on the composite surfaces. A detailed analysis of bubble detachment is presented in the next section.

\section{Mechanism of the Bubble Detachment}

It is well known that various models have been developed ${ }^{17,18}$ to describe fluid flow and heat transfer associated with bubble growth. All of these models assume a fixed three-phase line (TPL) and an evaporating film at the TPL region with very high evaporative heat fluxes of theoretically up to $10^{7} \sim 10^{8} \mathrm{~W} / \mathrm{m}^{2}$. Unfortunately, validation of these models is impossible at the microscopic level for lack of direct measurement technology in the region of the TPL. Recently, Mitrovic ${ }^{19,20}$ demonstrated that 1 ) the TPL is not fixed and the profile of the TPL region is concave-convex for rapid evaporation at the tip of the liquid wedge formed along the rim of the growing bubble and 2) the TPL moves outward during the gross bubble growth period but turns inward before bubble detachment.

In highly wetting fluids, such as Freon-113, bubbles that are attached to a metal surface maintain a spherical shape until their departure, ${ }^{21,22}$ whereas those in boiling water take a teardrop shape and depart from the boiling surface through necking. ${ }^{16,23}$ The major difference between the two liquids is that the bubbles in water undergo a necking process, but these in Freon-113 do not. However, both liquids have a movable TPL on the wall surface. A bubble on a metal surface in highly wetting liquids nucleates at a cavity and forms a spherical shape. During its growth, the TPL expands outward accompanied by changes in its profile to a concave-convex curve under the combined action of a high evaporation rate and Laplace pressure, maintaining the contact angle below 90 deg as a result of its high-wetting nature. As the bubble grows further, the Laplace pressure is reversed, and the hydrostatic pressure on the liquid side increases, resulting in cessation of the TPL's expansion and subsequent reversal of the TPL motion. During the process of bubble growth, the buoyancy force increases while the surface tension force decreases as the TPL moves inwards. When the buoyancy force exceeds the surface tension force, the bubble departs from the wall surface. In case of water with lower wettability and higher surface tension, the TPL has a greater tendency to move outward resulting in the profile of the liquid-vapor interface near the wall not only changing to a convex-concave shape but also curving further along the wall surface, thus forming an obtuse contact angle and creating a neck (throat) near the wall. ${ }^{19}$ As bubble growth progresses, the neck is lifted, narrowed, and finally breaks off under the action of the buoyancy force.

\section{Enhancement Effect of Graphite Fibers on Boiling}

Even for the highly wetting liquids, such as Freon-113, a combination of poor wetting properties and very high thermal conductivity of graphite fibers causes embryo bubbles to sit on the fiber tips with a neck, ${ }^{13,24}$ as shown in Fig. 7a. Subsequently, the TPL moves outward as the arrows indicate in Fig. $7 \mathrm{~b}$ causing the bubble to neck, and then the TPL moves inward as the arrows indicate in Fig. 7c with a lifted neck on the bubble. Finally, the bubble breaks off at the necked-down section, as shown in Fig. 7d. An analysis of the necking process in Ref. 24 indicated that the continuously increasing vapor velocity caused by reduction in the throat diameter promotes the necking to proceed until a pressure balance is reached between the vapor and the liquid at the neck. In the course of the necking, the buoyancy force on the bubble increases with bubble growth, accompanied by a decrease in the surface-tension force at the throat of the bubble until the bubble is cut off at the neck. 


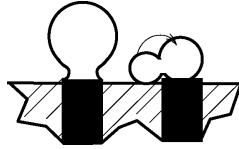

a)

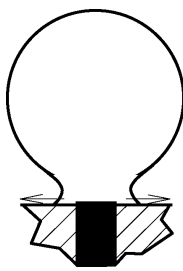

b)

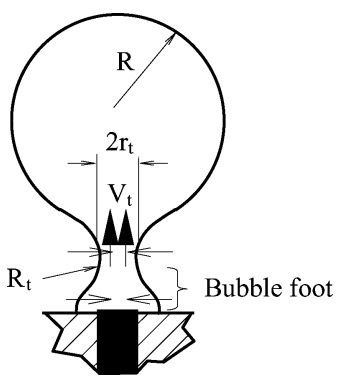

c)

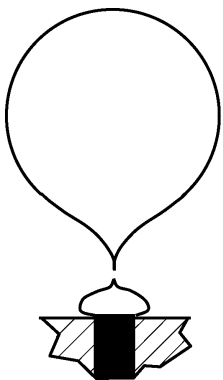

d)

Fig. 7 Bubble departure process from $\mathrm{Cu}-\mathrm{Gr}$ composite surface.

The dynamic equation for the necking process can be derived by applying the pressure balance ${ }^{25}$ at the throat:

$$
\sigma / r_{t}-\sigma / R_{t}=\left(\rho_{v} V_{t}^{2}-\rho_{l} \dot{r}_{t}^{2}\right) / 2
$$

At the moment before the neck breaks off, the curvature $R_{t}$ becomes very large while the liquid velocity $\dot{r}_{t}$ becomes relatively small. Thus, Eq. (4) can be simplified to yield the throat radius as

$$
r_{t}=2 \sigma /\left(\rho_{v} V_{t}^{2}\right)
$$

Mass conservation of the vapor phase gives the vapor velocity at the throat as

$$
V_{t}=q_{f} /\left(\varepsilon^{2} \rho_{v} h_{\mathrm{fg}}\right)
$$

Here, $q_{f}$ is the local heat flux at the bubble foot area, obtained by an integral average of heat flux over the TPL region. Meanwhile, the force balance at the throat ${ }^{21}$ yields

$$
r_{t} \sigma+\left[\left(\rho_{l}-\rho_{v}\right) g R-\sigma / R\right] r_{t}^{2}-2 R^{3}\left(\rho_{l}-\rho_{v}\right) g / 3=0
$$

A substitution of Eq. (5) into Eq. (7) to eliminate $r_{t}$ yields

$$
\begin{aligned}
& 2 \sigma^{2} / \rho_{v} V_{t}^{2}+\left(2 \sigma / \rho_{v} V_{t}^{2}\right)^{2}\left[\left(\rho_{l}-\rho_{v}\right) g R-\sigma / R\right] \\
& =\left(2 R^{3} / 3\right)\left(\rho_{l}-\rho_{v}\right) g
\end{aligned}
$$

which relates the departure radius to $q_{f}$ and $\varepsilon$ through Eq. (6).

Equation (8) combined with Eq. (6) suggests that the higher the value of $q_{f}$, the smaller the departure radius is. For example, let us take $\varepsilon \approx 0.1$ and $q_{f} \approx 10^{5} \sim 10^{6} \mathrm{~W} / \mathrm{m}^{2}$ for water boiling on a pure copper surface and $q_{f} \approx 10^{6} \sim 10^{7} \mathrm{~W} / \mathrm{m}^{2}$ for boiling on $\mathrm{Cu}-\mathrm{Gr}$ composite surfaces in the discrete bubble region. The thermal properties of both the saturated vapor and liquid phases of water at the boiling point are available in Ref. 26 . The relevant data include $\sigma=0.059 \mathrm{~N} / \mathrm{m}, \rho_{l}=958.1 \mathrm{~kg} / \mathrm{m}^{3}, \rho_{v}=0.597 \mathrm{~kg} / \mathrm{m}^{3}$, and $h_{\mathrm{fg}}=2.26 \times 10^{6} \mathrm{~J} / \mathrm{kg}$. Then, a calculation utilizing Eqs. (6) and (8) yields $R \approx 0.7 \sim 3.2 \mathrm{~mm}$ for water on a pure copper surface and $R=0.15 \sim 0.7 \mathrm{~mm}$ for water on the $\mathrm{Cu}-\mathrm{Gr}$ composite surfaces. Both departure radii agree with our experimental observations. Figure 8 shows photographs of water bubble departure during the initial stages of nucleate boiling. The corresponding bubble departure diameters are determined to be about $2.6 \mathrm{~mm}$ on the pure copper surface (Fig. 8a) and $0.3 \mathrm{~mm}$ on the $\mathrm{Cu}-\mathrm{Gr}$ composite surface (Fig. 8 b) with $\phi=25 \%$. A few bubbles about $2 \mathrm{~mm}$ in diameter seen in Fig. $8 \mathrm{~b}$ were located at the interface of the boiling surface and the G-11 extension frame where the superheat was very low. These bubbles stayed same and had nothing to do with the boiling.

The preceding analysis of the necking process has revealed that the local heat flux at the bubble foot area determines the bubble departure diameter. This phenomenon occurs in the micrographite fiber because of the very high thermal conductivity of the graphite material combined with very high fiber tip temperature. The bubble departure diameter is reduced with an increase in the speed of the necking process, resulting in an increased bubble departure frequency. Furthermore, at very high temperature, microsized trenches and grooves on the protruding fiber tips serve as nucleation sites to generate bubbles.

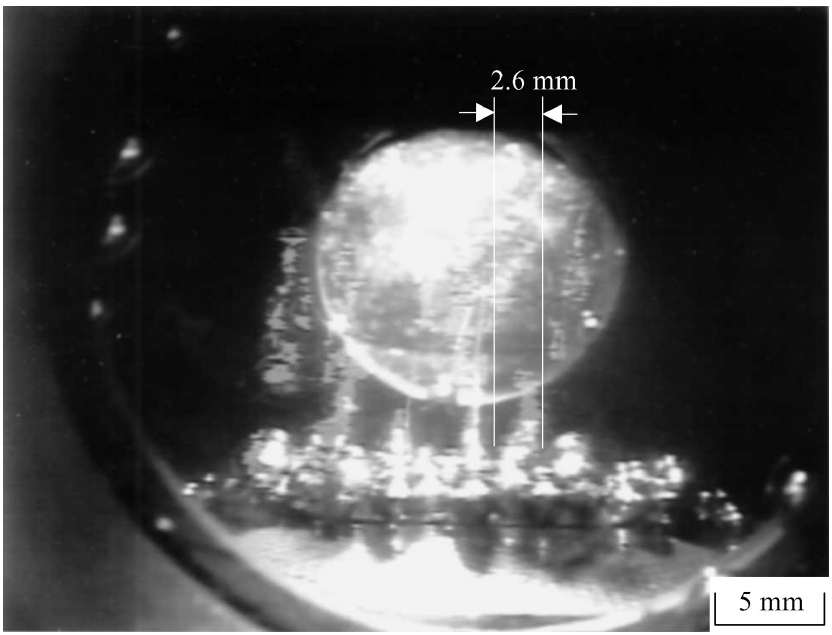

a)



b)

Fig. 8 Photos of water bubble departure in the initial stages of nucleate boiling: a) on pure copper surface at $\Delta T_{\text {sat }}=11 \mathrm{~K}$, departure diameter $D \approx 2.6 \mathrm{~mm}$; b) on $\mathrm{Gr}-\mathrm{Cu}$ composite surface $(\phi=0.25)$ at $\Delta T_{\text {sat }}=7 \mathrm{~K}$, departure diameter $D \approx 0.3 \mathrm{~mm}$.

\section{Conclusions}

An experimental study has been conducted on atmospheric nucleate pool boiling of a highly wetting liquid, Freon-113, and a moderately wetting liquid, water, on copper-graphite composite surfaces having various fiber volume fractions. Results have indicated a significant enhancement in the boiling heat-transfer performance in both Freon-113 and water. Best-fit correlations have been derived, which relate the boiling heat flux to the wall superheat and the boiling heat-transfer coefficient to the heat flux for each liquidsolid combination. The volume fraction of graphite fiber of $25 \%$ in 
a copper matrix achieved the best enhancement in both Freon-113 and water, but higher in water than in Freon-113. This enhancement was accompanied by a reduction in the incipient boiling superheat for Freon-113 and water by 40 and 35\%, respectively, and an enhancement of the boiling heat flux for Freon-113 and water up to 10-fold and 6.7-fold, respectively. The extent of enhancement is dependent on the degree of wall superheat. An empirical regression equation that relates heat flux to wall superheat in the nucleate pool boiling region has been derived. This has led to defining the enhancement factor as a function of the wall superheat for the metalgraphite composite surface with respect to its pure metal matrix. The enhancement potential of all $\mathrm{Cu}-\mathrm{Gr}$ composite surfaces on the boiling heat transfer diminishes with an increase in heat flux in both Freon-113 and water, but with less degeneracy of enhancement in water. An analysis has been performed to determine enhancement mechanism of nucleate pool boiling on the composite surfaces. The dynamic equation of the necking process during the growth of an attached bubble at a nucleation site has been derived by applying a force balance at the bubble throat. It is found that an increase in local heat flux at the foot of a bubble that is located on a graphite fiber tip reduces the bubble departure diameter resulting from acceleration of the necking process.

\section{References}

${ }^{1}$ Bland, T. J., Downing, R. S., and Rogers, D. P., "A Two-Phase Thermal Management System for Large Space Platforms," AIAA Paper 84-1578, June 1984.

${ }^{2}$ Ellis, W. E., "The Space Station Active Thermal Control Technical Challenge," AIAA Paper 89-0073, Jan. 1989.

${ }^{3}$ Ungar, E. K., "Single Phase vs. Two-Phase Active Thermal Control Systems for Space Applications: A Trade Study," AIAA Paper 95-0634, Jan. 1995.

${ }^{4}$ Williams, R. B., and Best, F. R., "Two-Phase Flow Regime Management for Inspace Power Rejection Management-Feasibility Study," Proceedings of the 30th Intersociety Energy Conversion Engineering Conference, Vol. 1, American Society of Mechanical Engineers, Fairfield, NJ, 1995, pp. $583-588$.

${ }^{5}$ Thome, J. R., Enhanced Boiling Heat Transfer, Hemisphere, New York, 1990, Chap. 3.

${ }^{6}$ Yang, W. J., Takizawa, H., and Varable, D., "Augmented Boiling on Copper-Graphite Composite Surface," International Journal of Heat and Mass Transfer, Vol. 34, No. 11, 1991, pp. 2751-2758.

${ }^{7}$ Zhang, N., Yang, W. J., Yang, G. W., “Two-Tier Model for Nucleate Pool Boiling on Micro Configured Composite Surfaces," International Communications in Heat and Mass Transfer, Vol. 19, No. 6, 1992, pp. 767-779.

${ }^{8}$ Yang, G. W., Yang, W. J., and Zhang, N., "Mechanisms of Nucleate Pool Boiling on Composite Surfaces," International Communications in Heat and Mass Transfer, Vol. 19, No. 6, 1992, pp. 781-790.

${ }^{9}$ Yang, G. W., "Micro- and Macro-Phenomena in Nucleate Pool Boiling on Graphite-Copper Composite Materials," Ph.D. Dissertation, Dept. of Mechanical Engineering and Applied Mechanics, Univ. of Michigan, Ann Arbor, May 1995.
${ }^{10}$ Yang, G. W., Liang, H.-S., Yang, W. J., and Vrable, D. L., "Nucleate Pool Boiling on Micro Graphite-Copper Composite Surfaces," Journal of Heat Transfer, Vol. 118, No. 4, 1996, pp. 792-796.

${ }^{11}$ Liang, H.-S., "Nucleate Pool Boiling on Micro-Graphite-Fiber Composite Surfaces with Applications in Micro-Electronic Cooling," Ph.D. Dissertation, Dept. of Mechanical Engineering and Applied Mechanics, Univ. of Michigan, Ann Arbor, May 1997.

${ }^{12}$ Yang, W. J., and Zhang, N., "A Theoretical Treatment of Critical Heat Flux on Metal-Graphite Heating Surfaces," Proceedings of the ASME Heat Transfer Division, Vol. 2 (HTD-Vol. 364-2), American Society of Mechanical Engineers, New York, 1999, pp. 315-320.

${ }^{13}$ Zhang, N., Chao, D. F., and Yang, W. J., "Enhancements of Nucleate Boiling and Critical Heat Flux under Microgravity Conditions," Journal of Thermophysics and Heat Transfer, Vol. 15, No. 3, 2001, pp. 326-332.

${ }^{14}$ Liang, H.-S., and Yang, W. J., "Nucleate Pool Boiling Heat Transfer in a Highly Wetting Liquid on Micro-Graphite-Fiber Composite Surfaces," International Journal of Heat and Mass Transfer, Vol. 41, No. 13, 1998, pp. 1993-2001.

${ }^{15}$ Coleman, H. W., and Steele, W. G., Experimentation and Uncertainty Analysis for Engineers, 2nd ed., Wiley, New York, 1999.

${ }^{16}$ Gaertner, R. F., "Photographic Study of Nucleate Pool Boiling on a Horizontal Surface," Journal of Heat Transfer, Vol. 87-C, No. 1, 1965, pp. 17-29.

${ }^{17}$ Lay, J. H., and Dihr, V. K., "Shape of a Vapor Stem During Nucleate Boiling of Saturated Liquids," Journal of Heat Transfer, 1995, Vol. 117, No. 2, pp. 394-401.

${ }^{18}$ Hammer, J., and Stephan, P., "The Role of Micro-Region Phenomena on Nucleate Boiling Heat Transfer," Proceedings of the 2nd European Thermal-Science, Vol. 1, Edizioni ETS, Pisa, Italy 1996, pp. 467-474.

${ }^{19}$ Mitrovic, J., "Formation of a Liquid Jet after Detachment of a Vapour Bubble," International Journal of Heat and Mass Transfer, Vol. 40, No. 18, 1997, pp. 4309-4317.

${ }^{20}$ Mitrovic, J., "The Flow and Heat Transfer in the Wedge-Shaped Liquid Film Formed During the Growth of a Vapour Bubble," International Journal of Heat and Mass Transfer, Vol. 41, No. 12, 1998, pp. 1771-1785.

${ }^{21}$ Beer, H., Burow, P., and Best, R., "Bubble Growth, Bubble Dynamics, and Heat Transfer in Nucleate Boiling, Viewed with a Laser Interferometer," Heat Transfer in Boiling, edited by E. Hahne and U. Grigull, Academic Press, New York, 1977, pp. 21-52.

${ }^{22}$ Klausner, J. F., Mei, R., Bernhard, D. M., and Zeng, L. Z., "Vapor Bubble Departure in Forced Convection Boiling," International Journal of Heat and Mass Transfer, Vol. 36, No. 3, 1993, pp. 651-662.

${ }^{23}$ Mori, B. K., and Baines, W. D., "Bubble Departure from Cavities," International Journal of Heat and Mass Transfer, Vol. 44, No. 4, 2001, pp. 771-783.

${ }^{24}$ Zhang, N., Chao, D. F., and Yang, W. J., "Characteristics of Pool Boiling on Graphite-Copper Composite Surfaces," NASA/TM-2002-211211, 2002, pp. 197, 198.

${ }^{25}$ Carey, V. P., Liquid-Vapor Phase-Change Phenomena, Hemisphere, London, 1992, Chap. 4.

${ }^{26}$ Vargaftik, N. B., Handbook of Physical Properties of Liquids and Gases, Hemisphere, Washington, DC, 1983. 